\title{
The Insertion/Deletion Polymorphism of Angiotensin I Converting Enzyme Gene is Associated With Ossification of the Posterior Longitudinal Ligament in the Korean Population
}

\author{
Dong Hwan Kim, $\mathrm{MD}^{1}$, Dong Hwan Yun, $\mathrm{MD}^{1}$, Hee-Sang Kim, $\mathrm{MD}^{1}$, Seong Ki Min, $\mathrm{MD}^{1}$, \\ Seung Don Yoo, $\mathrm{MD}^{1}$, Kyu Hoon Lee, $\mathrm{MD}^{2}$, Ki-Tack Kim, $\mathrm{MD}^{3}$, Dae Jean Jo, $\mathrm{MD}^{4}$, \\ Su Kang Kim, $\mathrm{PhD}^{5}$, Joo-Ho Chung, $\mathrm{MD}^{5}$, Ju Yeon Ban, $\mathrm{PhD}^{6}$, Sung Yong Lee, $\mathrm{MD}^{1}$
}

\begin{abstract}
${ }^{1}$ Department of Physical Medicine \& Rehabilitation, Kyung Hee University School of Medicine, Seoul; ${ }^{2}$ Department of Physical Medicine \& Rehabilitation, Hanyang University College of Medicine, Seoul; Departments of ${ }^{3}$ Orthopedic Surgery and ${ }^{4}$ Neurosurgery, ${ }^{5}$ Kohwang Medical Research Institute, Kyung Hee University School of Medicine, Seoul; ${ }^{6}$ Department of Dental Pharmacology, Dankook University College of Dentistry, Cheonan, Korea
\end{abstract}

Objective To determine whether ACE insertion/deletion (I/D) polymorphism is associated with the ossification of the posterior longitudinal ligament (OPLL) of the spine in the Korean population.

Methods A case-control study was conducted to investigate the association between I/D polymorphism of the angiotensin I converting enzyme (peptidyl-dipeptidase A) 1 (ACE) gene and OPLL. The 95 OPLL patients and 274 control subjects were recruited. Polymerase chain reaction for the genotyping of ACE I/D polymorphism was performed. The difference between the OPLL patients and the control subjects was compared using the contingency $\chi^{2}$ test and the logistic regression analysis. For statistical analysis, SPSS, SNPStats, SNPAnalyzer, and Helixtree programs were used.

Results The genotype and allele frequencies of ACE I/D polymorphism showed significant differences between the OPLL patients and the control subjects (genotype, $\mathrm{p}<0.001$; allele, $\mathrm{p}=0.009$ ). The frequencies of $\mathrm{D} / \mathrm{D}$ genotype and D allele in the OPLL group were higher than those in the control group. In logistic regression analysis, ACE I/ D polymorphism was associated with OPLL (dominant model; $\mathrm{p}=0.002$; odd ratio, 2.20; 95\% confidence interval, 1.33-3.65).

Conclusion These results suggest that the deletion polymorphism of the ACE gene may be a risk factor for the development of OPLL in the Korean population.

Keywords Ossification of the posterior longitudinal ligament, Angiotension converting enzyme, Genetic polymorphism, Genetic association analysis

Department of Physical Medicine \& Rehabilitation, Kyung Hee University School of Medicine, 26 Kyungheedae-ro, Dongdaemun-gu, Seoul 130-701, Korea Tel: +82-2-440-7246, Fax: +82-2-440-7260, E-mail: stylistlsy@gmail.com

@ This is an open-access article distributed under the terms of the Creative Commons Attribution Non-Commercial License (http://creativecommons.org/ licenses/by-nc/3.0) which permits unrestricted noncommercial use, distribution, and reproduction in any medium, provided the original work is properly cited. Copyright $\odot 2014$ by Korean Academy of Rehabilitation Medicine 


\section{INTRODUCTION}

Ossification of the posterior longitudinal ligament (OPLL) has been known as a multifactorial disease [1,2]. The most characteristic symptom of OPLL is myelopathy resulting from the compression of the spinal cord; other signs and symptoms include sensory dysfunction of the upper and the lower extremities, motor weakness, an increased deep tendon reflex, and neurogenic bladder and bowel [3]. Genetic factors are considered to play an important role in the etiology of OPLL based on nationwide pedigree surveys, twins surveys, and human leukocyte antigen (HLA) haplotype analysis $[2,4,5]$. Recently, the relationship between single-nucleotide polymorphisms (SNPs) in various genes and OPLL has been studied. A case-control association and sib-pair linkage studies have shown that several genes are related to the susceptibility to OPLL. These include genes for collagen, type VI, alpha 1 (COL6A1), collagen, type XI, alpha 2 (COL11A2), bone morphogenetic protein 2 (BMP2), ectonucleotide pyrophosphatase/phosphodiesterase 1 (ENPP1), estrogen receptor 1 (ESR1), interleukin-1 beta (IL1B), leptin receptor, and transforming growth factor beta 1 (TGFB1) [6-16].

In this study, 768 DNA chips were used to investigate whether SNPs of several genes are associated with the occurrence of OPLL, and angiotensin I converting enzyme (peptidyl-dipeptidase A) 1 (ACE) was found to have a relationship with susceptibility to OPLL. ACE has a major role in the renin-angiotensin system, and it also inactivates the bradykinin, a vasodilator, in the kallikrein-kinin system [17]. An insertion/deletion (I/D) polymorphism in intron 16 of the ACE gene (NCBI, dbSNP database, BUILD 129) was found to be associated with plasma and cellular ACE levels [18], so primers for ACE I/D polymorphism were selected for this study. The ACE I/D polymorphism in OPLL patients has not been reported yet. In this study, we report the association between ACE I/D polymorphism and OPLL in the Korean population.

\section{MATERIALS AND METHODS}

\section{Subjects}

This study protocol was approved by the Ethics Committee of the Medical Research Institute, Kyung Hee University Hospital at Gangdong, Korea. This study was conducted on 95 patients with OPLL who visited the outpatient clinic or were hospitalized at The Spine Center at Kyung Hee University Hospital and the Department of Physical Medicine \& Rehabilitation of Kyung Hee Medical Center. The OPLL patients were diagnosed by computed tomography, magnetic resonance imaging, and/or radiograph findings. The patients with a spinal operation, other spinal diseases, such as myelopathy, spinal tumor, spinal fracture, were excluded. Healthy control subjects $(n=274)$ with no evidence of OPLL in cervical X-ray were recruited after a general health check-up program confirmed that they had no clinical evidence of any severe diseases, such as stroke, diabetes, myocardial infarction, and psychiatric disorders. The OPLL group consisted of 53 males (61.67 \pm 11.39 years) and 42 females $(61.14 \pm 15.23$ years). The control group was comprised of 182 males (58.46 \pm 5.89 years) and 92 females (53.3 \pm 13.73 years).

DNA samples and genotyping of ACE I/D polymorphism

Blood samples were obtained from all the participants with informed written consent. Genomic DNA was extracted from blood samples using QIAamp DNA mini kit (QIAGEN, Valencia, CA, USA). Genomic DNA was amplified using the following primers for ACE I/D polymorphism (sense, 5'-CTG GAG ACC ACT CCC ATC CTT TCT3'; antisense, 5' -GAT GTG GCC ATC ACA TTC GTC AGA T-3'; size, $480 \mathrm{bp}$ ). Polymerase chain reaction (PCR) was 35 cycles at $94^{\circ} \mathrm{C}$ for 30 seconds, $58^{\circ} \mathrm{C}$ for 30 seconds, $72^{\circ} \mathrm{C}$ for 1 minute, and 1 cycle at $72^{\circ} \mathrm{C}$ for 7 minutes to terminate the reaction. The PCR products were identified with $1.5 \%$ agarose gel electrophoresis.

\section{Statistical analysis}

A statistical analysis was performed using the SPSS software (SPSS Inc., Chicago, IL, USA). The chi-square $\left(\chi^{2}\right)$ test was used to value Hardy-Weinberg equilibrium. A logistic regression analysis controlling age and sex as co-variables in three models (codominant, dominant, and recessive model) was performed using SNPAnalyzer (ISTECH Inc., Goyang, Korea), Helixtree (Golden Helix Inc., Bozeman, MT, USA), and SNPstats (http://bioinfo. iconcologia.net/index.php) $[19,20]$. A p-value less than 0.05 was considered as statistically significant. 


\section{RESULTS}

In this study, we investigated whether ACE I/D polymorphism is associated with OPLL in the Korean population. We calculated the exact size of the PCR product for genotypes of ACE I/D polymorphism (rs4646994) using NCBI website (http://www.ncbi.nlm.gov/SNP/, BUILD 129; ALFRED [the Allele Frequency Database], 285-bp Alu). As shown in Fig. 1, the I/D genotype was observed at $480 \mathrm{bp}$ and $195 \mathrm{bp}$. The deletion homozygote (D/D) and the insertion homozygote (I/I) were observed at 195 bp and $480 \mathrm{bp}$, respectively.

The genotype and the allelic frequencies of I/D polymorphism of the $A C E$ gene in the control subjects and the OPLL patients are shown in Table 1. No deviation of Hardy-Weinberg equilibrium was found in the control group. The frequencies of I/I and D/D genotypes were

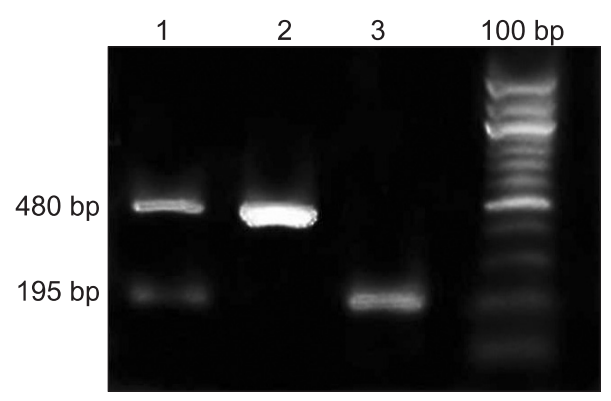

Fig. 1. Electrophoresis of polymerase chain reaction products of $A C E$ gene. Lane 1 is the insertion/deletion heterozygote (I/D). Lane 2 is the insertion homozygote (I/ I). Lane 3 is the deletion homozygote (D/D). ACE, angiotensin I converting enzyme.
$28.5 \%$ and $25.6 \%$ in the control group, and $27.4 \%$ and $46.3 \%$ in the OPLL group, respectively. The frequency of I/D genotype was $46.0 \%$ in the control group and $26.3 \%$ in the OPLL group. The frequencies of I and D alleles were $51.5 \%$ and $48.5 \%$ in the control group, and $40.5 \%$ and $59.5 \%$ in the OPLL group, respectively. There were statistically significant differences in the genotype and the allelic frequencies between the control group and the OPLL group (genotype, $\mathrm{p}<0.001$; allele, $\mathrm{p}=0.009$ ) (Table 1 ).

A logistic regression analysis in three models (codominant, dominant, and recessive models) was used for odds ratio (OR), 95\% confidence interval (CI), and a corresponding $\mathrm{p}$-value, controlling age and sex as co-variables.

Table 1. Genotype and allele frequencies of $A C E$ gene in the control subjects and the patients with OPLL

\begin{tabular}{lrrr}
\hline & $\begin{array}{c}\text { OPLL } \\
(\mathbf{n = 9 5})\end{array}$ & $\begin{array}{c}\text { Control } \\
(\mathbf{n = 2 7 4})\end{array}$ & p-value $^{\text {a) }}$ \\
\hline Genotype & & & $<0.001$ \\
I/I & $26(27.4)$ & $78(28.5)$ & \\
\hline I/D & $25(26.3)$ & $126(46.0)$ & \\
D/D & $44(46.3)$ & $70(25.5)$ & \\
\hline Allele & & & 0.009 \\
\hline I & $77(40.5)$ & $282(51.5)$ & \\
\hline D & $113(59.5)$ & $266(48.5)$ & \\
\hline
\end{tabular}

Values are presented as number (\%).

ACE, angiotensin I converting enzyme; OPLL, ossification of the posterior longitudinal ligament; I/I, insertion/insertion; I/D, insertion/deletion; D/D, deletion/ deletion.

a) -value was calculated by chi-square $\left(\chi^{2}\right)$ test using SAS ver. 9.1.

Table 2. A logistic regression analysis of $A C E$ gene in the control subjects and the patients with OPLL

\begin{tabular}{llcccc}
\hline \multicolumn{1}{c}{ Model } & Genotype & OPLL $(\mathbf{n}=\mathbf{9 5})$ & Control (n=274) & OR (95\% CI) & p-value $^{\text {a) }}$ \\
\hline Codominant & D/D & $44(46.3)$ & $70(25.5)$ & - & 0.084 \\
& I/D & $25(26.3)$ & $126(46.0)$ & $1.32(0.96-1.82)$ & \\
\hline & I/I & $26(27.4)$ & $78(28.5)$ & - & \\
\hline & D/D & $44(46.3)$ & $70(25.6)$ & - & 0.002 \\
\hline \multirow{2}{*}{ Recessive } & I/D-I/I & $51(53.7)$ & $204(74.4)$ & $2.20(1.33-3.65)$ & \\
& D/D-I/D & $69(72.6)$ & $196(71.5)$ & - & 0.790 \\
\hline
\end{tabular}

Values are presented as number (\%).

ACE, angiotensin I converting enzyme; OPLL, ossification of the posterior longitudinal ligament; OR, odds ratio; CI, confidence interval; I/I, insertion/insertion; I/D, insertion/deletion; D/D, deletion/deletion.

a) p-values were calculated by a logistic regression analysis with co-dominant, dominant, and recessive models controlling age and gender as covariates. 
In logistic analysis, we found a significant association between ACE I/D polymorphism and OPLL (dominant model; $\mathrm{p}=0.002$; OR, 2.20; 95\% CI, 1.33-3.65) (Table 2).

\section{DISCUSSION}

In this study, we compared the genotype frequencies of ACE I/D polymorphism in 15 intron of the ACE gene between the control subjects and the OPLL patients. We found a significant degree of association between ACE I/ D polymorphism and OPLL (genotype, $\mathrm{p}<0.001$; allele, $\mathrm{p}=0.009$ ) (Table 1). Comparing the genotype frequencies in the dominant model (D/D vs. D/I and I/I), we found that the frequency of $\mathrm{D} / \mathrm{I}$ and $\mathrm{I} / \mathrm{I}$ in the OPLL group (53.7\%) was lower than that in the control group (74.4\%), whereas the frequency of D/D in the OPLL group (46.3\%) was higher than that in the control group $(25.6 \%)$. The difference was statistically significant between the OPLL patients and the control subjects ( $\mathrm{p}=0.002 ; \mathrm{OR}, 2.20 ; 95 \%$ CI, 1.33-3.65) (Table 2). The result indicates that the $\mathrm{D} / \mathrm{D}$ genotype of ACE I/D polymorphism may be a risk factor in the development of OPLL in the Korean population.

OPLL is one of the bone-forming diseases, characterized by an ectopic ossification in the spine ligaments $[21,22]$. Although the etiology of OPLL is not fully defined, genetic background is considered to be a major factor in the development of OPLL. Several studies on the relationship between OPLL and HLA haplotypes in families of the patients with OPLL suggested that genetic factors may play a role in the pathogenesis of OPLL $[2,5]$. Maeda et al. [8] found a male-specific association of a COL11A2 haplotype with OPLL. Tanaka et al. [23] reported that SNPs in the COL6A1 gene were strongly associated with OPLL. Plasma ACE levels are associated with the ACE I/ D polymorphism $[24,25]$. Individuals who were homozygous to the D/D genotype showed a high activity of ACE, while those with either I/D or I/I genotype showed a low activity of ACE. Yoshida et al. [26] suggested that homozygote $\mathrm{D} / \mathrm{D}$ is a risk factor for the progression to a chronic renal failure in IgA nephropathy.

In conclusion, the present study shows the association between ACE I/D polymorphism and OPLL in the Korean population. The frequencies of $\mathrm{D} / \mathrm{D}$ genotype and $\mathrm{D}$ allele in the OPLL patients are higher than those in the control subjects. These results suggest that the deletion polymorphism of the ACE gene may be a risk factor for the development of OPLL.

\section{CONFLICT OF INTEREST}

No potential conflict of interest relevant to this article was reported.

\section{ACKNOWLEDGMENTS}

This paper was supported by the Kyung Hee University Research Fund in 2007 (KHU-20071395).

\section{REFERENCES}

1. Inamasu J, Guiot BH, Sachs DC. Ossification of the posterior longitudinal ligament: an update on its biology, epidemiology, and natural history. Neurosurgery 2006;58:1027-39.

2. Matsunaga S, Yamaguchi M, Hayashi K, Sakou T. Genetic analysis of ossification of the posterior longitudinal ligament. Spine (Phila Pa 1976) 1999;24:937-8.

3. Mizuno J, Nakagawa H. Ossified posterior longitudinal ligament: management strategies and outcomes. Spine J 2006;6(6 Suppl):282S-288S.

4. Koga H, Sakou T, Taketomi E, Hayashi K, Numasawa $\mathrm{T}$, Harata $\mathrm{S}$, et al. Genetic mapping of ossification of the posterior longitudinal ligament of the spine. Am J Hum Genet 1998;62:1460-7.

5. Sakou T, Taketomi E, Matsunaga S, Yamaguchi M, Sonoda S, Yashiki S. Genetic study of ossification of the posterior longitudinal ligament in the cervical spine with human leukocyte antigen haplotype. Spine (Phila Pa 1976) 1991;16:1249-52.

6. Kong Q, Ma X, Li F, Guo Z, Qi Q, Li W, et al. COL6A1 polymorphisms associated with ossification of the ligamentum flavum and ossification of the posterior longitudinal ligament. Spine (Phila Pa 1976) 2007;32:2834-8.

7. Koga H, Hayashi K, Taketomi E, Matsunaga S, Yashiki S, Fujiyoshi T, et al. Restriction fragment length polymorphism of genes of the alpha 2(XI) collagen, bone morphogenetic protein-2, alkaline phosphatase, and tumor necrosis factor-alpha among patients with ossification of posterior longitudinal ligament and controls from the Japanese population. Spine (Phila Pa 1976) 1996;21:469-73.

8. Maeda S, Koga H, Matsunaga S, Numasawa T, Ikari 
$\mathrm{K}$, Furushima K, et al. Gender-specific haplotype association of collagen alpha2 (XI) gene in ossification of the posterior longitudinal ligament of the spine. $\mathrm{J}$ Hum Genet 2001;46:1-4.

9. Maeda S, Ishidou Y, Koga H, Taketomi E, Ikari K, Komiya S, et al. Functional impact of human collagen alpha2(XI) gene polymorphism in pathogenesis of ossification of the posterior longitudinal ligament of the spine. J Bone Miner Res 2001;16:948-57.

10. Horikoshi T, Maeda K, Kawaguchi Y, Chiba K, Mori K, Koshizuka $Y$, et al. A large-scale genetic association study of ossification of the posterior longitudinal ligament of the spine. Hum Genet 2006;119:611-6.

11. Furushima K, Shimo-Onoda K, Maeda S, Nobukuni T, Ikari $\mathrm{K}$, Koga $\mathrm{H}$, et al. Large-scale screening for candidate genes of ossification of the posterior longitudinal ligament of the spine. J Bone Miner Res 2002;17:128-37.

12. Nakamura I, Ikegawa S, Okawa A, Okuda S, Koshizuka Y, Kawaguchi H, et al. Association of the human NPPS gene with ossification of the posterior longitudinal ligament of the spine (OPLL). Hum Genet 1999;104:492-7.

13. Koshizuka Y, Kawaguchi H, Ogata N, Ikeda T, Mabuchi A, Seichi A, et al. Nucleotide pyrophosphatase gene polymorphism associated with ossification of the posterior longitudinal ligament of the spine. J Bone Miner Res 2002;17:138-44.

14. Ogata N, Koshizuka Y, Miura T, Iwasaki M, Hosoi T, Shiraki M, et al. Association of bone metabolism regulatory factor gene polymorphisms with susceptibility to ossification of the posterior longitudinal ligament of the spine and its severity. Spine (Phila Pa 1976) 2002;27:1765-71.

15. Tahara M, Aiba A, Yamazaki M, Ikeda Y, Goto S, Moriya $H$, et al. The extent of ossification of posterior longitudinal ligament of the spine associated with nucleotide pyrophosphatase gene and leptin receptor gene polymorphisms. Spine (Phila Pa 1976) 2005;30:877-80.

16. Kawaguchi Y, Furushima K, Sugimori K, Inoue I, Kimura T. Association between polymorphism of the transforming growth factor-betal gene with the radiologic characteristic and ossification of the posterior longitudinal ligament. Spine (Phila Pa 1976) 2003; 28:1424-6.

17. Viitanen L, Pihlajamaki J, Halonen P, Lehtonen M, Kareinen A, Lehto S, et al. Association of angiotensin converting enzyme and plasminogen activator inhibitor-1 promoter gene polymorphisms with features of the insulin resistance syndrome in patients with premature coronary heart disease. Atherosclerosis 2001;157:57-64.

18. Costerousse O, Danilov S, Alhenc-Gelas F. Genetics of angiotensin I-converting enzyme. Clin Exp Hypertens 1997;19:659-69.

19. Ban JY, Yoon KL, Kim SK, Kang S, Chung JH. Promoter polymorphism (rs3755724, -55C/T) of tissue inhibitor of metalloproteinase 4 (TIMP4) as a risk factor for Kawasaki disease with coronary artery lesions in a Korean population. Pediatr Cardiol 2009;30:331-5.

20. Jung MY, Kim BS, Kim YJ, Koh IS, Chung JH. Assessment of relationship between Fyn-related Kinase gene polymorphisms and overweight/obesity in Korean population. Korean J Physiol Pharmacol 2008;12:83-7.

21. Onji Y, Akiyama H, Shimomura Y, Ono K, Hukuda S, Mizuno S. Posterior paravertebral ossification causing cervical myelopathy: a report of eighteen cases. J Bone Joint Surg Am 1967;49:1314-28.

22. Tsuyama N. Ossification of the posterior longitudinal ligament of the spine. Clin Orthop Relat Res 1984;(184):71-84.

23. Tanaka T, Ikari K, Furushima K, Okada A, Tanaka H, Furukawa K, et al. Genomewide linkage and linkage disequilibrium analyses identify COL6A1, on chromosome 21 , as the locus for ossification of the posterior longitudinal ligament of the spine. Am J Hum Genet 2003;73:812-22.

24. Rigat B, Hubert C, Alhenc-Gelas F, Cambien F, Corvol $\mathrm{P}$, Soubrier F. An insertion/deletion polymorphism in the angiotensin I-converting enzyme gene accounting for half the variance of serum enzyme levels. J Clin Invest 1990;86:1343-6.

25. Rigat B, Hubert C, Corvol P, Soubrier F. PCR detection of the insertion/deletion polymorphism of the human angiotensin converting enzyme gene (DCP1) (dipeptidyl carboxypeptidase 1). Nucleic Acids Res 1992;20:1433.

26. Yoshida H, Mitarai T, Kawamura T, Kitajima T, Miyazaki $Y$, Nagasawa R, et al. Role of the deletion of polymorphism of the angiotensin converting enzyme gene in the progression and therapeutic responsiveness of IgA nephropathy. J Clin Invest 1995;96:2162-9. 